\title{
O ESPAÇO DA MULHER BRASILEIRA E O ESPAÇO DA ENFERMEIRA BRASILEIRA
}

\author{
Maria da Glória Miotto Wright ${ }^{1}$ e \\ Anamaria Carneiro ${ }^{2}$
}

\begin{abstract}
RESUMO. O presente artigo tece alguns comentários sobre o espaço que a mulher brasileira conquistou durante o decorrer dos anos e relaciona a conquista deste espaço dentro da profissão de enfermagem. Tenta mostrar os condicionantes da conquista deste espaço na sociedade brasileira e se, de fato, eles operaram da mesma forma no caso da mulher desempenhando o papel de enfermeira nesta mesma sociedade.
\end{abstract}

ABSTRACT. This article discusses changes in the status of brazilian women over the year and related the gains made to the nursing profession. It analyzes the factors in Brazilian society which condition the gains and if in fact they work in the same manner for nurses as for women in general.

\section{I - INTRODUÇĀO}

Por ser o Brasil uma nação complexa, diversificada e profundamente estratificada, é difícil a tarefa de escrever a história da mulher brasileira.

Tudo o que a maioria das pessoas sabe sobre a mulher é que ela deve ser boa mãe, dona de casa além de boa esposa. Um estudo consistente sobre a mulher brasileira deve incluir sua vida pública e privada, situação legal, vida familiar, poder político e os papéis econômicos e sociais desempenhados através da história.

1) A marginalidade da mulher nos processos de decisão e a história de sua discriminaçāo no trabalho, na educação e na política têm sido uma constante,' embora ela já tenha obtido algumas conquistas nesses campos. Entretanto, tais conquistas não eliminaram todas as dificuldades existentes de conciliação entre os papéis domésticos tradicionais da mulher (de dona de casa e de socializadora dos filhos) e de seus papéis profissionais (CARDOSO)? .

O abarcar dos dılerentes espaços que a mulher vem conquistando na sociedade, despertou-nos o interesse para analisar, tanto quanto possivel, o espaço dessa mesma mulher desempenhando o papel de enfermeira numa sociedade de sistema capitalista.

$\mathrm{Na}$ tentativa de buscar relaçōes entre o espaço da mulher e o da enfermeira na história brasileira, não podemos ignorar o quanto o capitalismo, com-

1 Professora Assistente do Curso de Enfermagem/UnB - aluna do Curso de Dottorado em Enfermagem da Escola de Enfermagem de Ribeiūo Preto/USP; bolsista do CNPq, CORLN n? 11587.

2 Professora Colaboradora 2 do Curso de Enfermagem/UnB. COREN nọ 11383-RJ. 
preendido como um modo histório de produção, tem interferido nestas conquistas.

Mesmo que se faça apenas uma análise limitada do modo de produção capitalista brasileiró, ela se torna importante para o embasamento teórico contido neste trabalho. $\mathbb{E}$ impossível querer compreender a situação da mulher brasileira e da enfermeira, neste País, sem levar em consideração as características da estrutura sócio-econômica do Brasil.

\section{II - A EVOLUÇÃO HISTÓRICA DO ESPAÇO DA MULHER BRASILEIRA}

A história da mulher em nosso País advém de meros registros de impressões, mais do que fatos. Sabe-se que existe necessidade de uma perspectiva e de uma compreensão histórica do papel, da condição e das atividades da mulher no Brasil.

Ao se estudar a evolução da história do espaço da mulher brasileira, precisa-se entender em que contexto ela ocorreu. Abordaremos, portanto, como evoluiu a situação da mulher na sociedade em relação à educação, ao trabalho, à política e à saúde.

\section{a) A Situaçâo da Mulher na Educação}

No período colonial, a mulher brasileira tinha uma oportunidade muito escassa de se educar, e no momento em que isto ocorria, reduzia-se à formação moral e religiosa e ao desenvolvimento de habilidades manuais. Em 1595, foi criado em Olinda o "Recolhimento da Conceição", com a finalidade de preparar as órfãs de boa familia para o casamen to (BARROS) ${ }^{2}$.

No século XVIII, começaram a aparecer os conventos religiosos. Em 1728, as moças recebiam o ensino equivalente ao $19 \mathrm{grau}$ além de canto, órgão e trabalhos domésticos. Esses conventos quase nada significaram em termos de educação para as mulheres, uma vez que atendiam a uma minoria.

$\mathrm{Na}$ época da Corte Portuguesa, houve alguns poucos benefícios para as mulheres, uma vez que se abriram algumas escolas não religiosas onde elas poderiam estudar. Recebiam o ensino de trabalhos manuais domésticos e conhecimentos rudimentares de Lingua Portuguesa.

Com a Independencia e a instalação do Governo Imperial, surge a idéia de estabelecer uma rede de escolas para atender à população. Em 1823, pela primeira vez, fala-se oficialmente em educação para as mulheres. Em 1824, a educação já passa a ser preocupação da Assembléia e os deputados propõem o ensino para as meninas. Nessa época era permitido à mulher, aprender apenas as quatro operaçōes, e os trabalhos manuais continuavam a ser o maior foco de atençōes. As mulheres eram proibidas de estudar em classes mistas. Em 1855, contavam-se oficialmente na corte: 17 escolas para meninos e 9 para meninas (CARDOSO) 7 .

Ao final do império, chegam ao Brasil várias missões protestantes, apresentando uma proposta educacional que valorizava o ensino de matérias cientificas, privilegiava os métodos empíricos e era a favor da co-educação. A influencia protestante não tinha, contudo, condiçōes de abalar a tradição católica dominante.

Por volta de 1870, os homens do Governo decidirarn implantar escolas profissionalizantes e foi declarado que o magistério de 19 grau seria ministrado, de preferência, às mulheres. Em 1875 , a Escola Caetano Campos, em São Paulo, foi a primeira a dar "emprego" às mulheres. Nesse mesmo período, surge o ensino secundário, destinado às pessoas que iriam cursar o nível superior, o que não era o caso das mulheres. Em 1879, o deputado Tobias Barreto exige o direito de matrícula em Medicina para uma moça. Somente em 1881 se registra o ingresso da primeira mulher em curso superior. Em 1884, os educadores expressam, através dos Pareceres do Congresso de Instrução, a co-educação.

A Proclamação da República não veio operar transformaçōes no sistema de ensino vigente. A Igreja Católica continuava a deter o poder da maior parte dos estabelecimentos de ensino e permanecia a separaçăa en tre o ensino teórico e o académico. Em 1907, duas moças, pela primeira vez, concluem o curso secundário de letras. Em 1929, as mulheres que ingressavam para o curso superior, iam para as escolas de Farmácia, porque era uma profissão que tinha sofrido grande desvalorização e nào interessava aos homens, e para o curso de música, porque era uma tradição, no Brasil, a mulher aprender a tocar piano. Além disso, surge um grande número de moças nos chamados cursos comerciais; as mulheres procuravam esses cursos porque davam oportunidades no mercado de trabalho (CARDOSO) $)^{7}$.

A Revolução de 1930 ampliou bastante os horizontes educacionais e sociais da mulher. Os cursos normais começaram a ser encarados com maior seriedade, exigindo-se, para seu ingresso, o diploma de ginásio e passando a ter a duração de 5 anos. Em 1942, ocorreu a reforma do ensino (Reforma Capanema), que marca novamente a discriminação 
contra a mulher, Essa lei sugeria a formação de classes exclusivamente femininas; assim, as mulheres deixam de fazer os cursos secundários e ingressam mais nos cursos normais.

Somente em 1939 é que as moças, depois do curso normal, obtiveram o direito de entrar em alguns cursos superiores (Pedagogia, Letras Neolatinas, Letras Anglo-Germânicas, Letras Clássicas, Geografia, História). Em 1953, caem, enfim, essas barreiras, podendo a normalista ingressar em qualquer curso superior.

- Até as décadas 60-70, eram poucas as mulheres que ainda ingressavam no curso superior, aumentando consideravelmente esse número a partir da última década.

b) A Situação da Mulher no Mercado de Trabalho

Desde o início do descobrimento do Brasil, a mulher tem, aos poucos, participado na força de trabalho, de maneira visível ou invisível.

$\mathrm{Na}$ época do Brasil Colônia, a ocupação mais comum era a de fiar algodão, executada, principalmente, pelas mulheres de cor. Muitas mulheres, tanto pretas como brancas, se ocupavam também em fazer renda. As escravas dedicavam-se à costura comum, pois essa ocupação era tida como degradante para os dedos de uma dama (HAH. NER $)^{10}$.

Ao final do século XIX, as mulheres eram empregadas em números sempre crescentes nas indústrias brasileiras, principalmente as têxteis, recebendo baixos salários.

Contudo, no início do século XX, o setor comercial oferecia números crescentes de empregos para a mulher. Apesar de tais empregos conferırem uma posição social algo mais elevada que o serviço doméstico, ambas as atividades permaneciam abaixo do ensino escolar (HAHNER) ${ }^{10}$.

Por volta da metade do século XX, o ensino primário torna-se uma atividade feminina compulsória. As mulheres proporcionalmente saíram das atividades industriais e se incorporaram mais intensamente no setor terciário da economia. A maioria das mulheres que trabalhava fora de seus lares dedicava-se a um pequeno número de ocupações.

BRUSCHINI $^{6}$ mostra que as ocupaçðes que já eram "femininas", em 1950, continuaram a sê-lo, em 1970, ainda que o percentual de mulheres no conjunto de trabalhadores tenha sofrido algumas alterações. Esse fato estaria provocando uma sexualização das ocupações. BARROSO ${ }^{3}$ mostra que a taxa de atividade feminina que era de $13,6 \%$, em 1950 , subiu para 18,5\%, em 1970, e $29,6 \%$, em 1976.

A partir de 1962, a Lei nọ 5.859 beneficia a empregada doméstica, concedendo-lhe o direito de férias anuais de 20 dias, a anotação na carteira de trabalho e a contribuição para o INPS.

$\mathrm{BRUSCHINI}^{6}$ salienta que, para as mulheres de classes menos favorecidas e com baixo nível de instrução, as possibilidades de trabalho limitam-se às ocupações relativas à prestação de serviços, quase sempre como empregadas domésticas e no trabalho de campo. A mulher de instrução mais elevada vai colocar-se nas ocupaçðes técnicas, científicas e afins, quando ingressa no mercado de trabalho. São, talvez, as mulheres de nível médio de instrução as que mais viram aumentadas as oportunidades de emprego nas últimas décadas, tanto nas ocupações administrativas como naquelas ligadas ao comércio.

Devemos lembrar que o trabaiho feminino, no seio da família, não produzia e nem produz diretamente mercadoria visível, assim ele não tem valor perante a sociedade. Quem o exerce tem sido, por esse fato, marginalizado da economia, da sociedade e da história. Por ser um trabalho invisível, a sua contribuição para o desenvolvimento das forças produtivas permanece na clandestinidade.

c) A Situação da Mulher na Política

Podemos dizer que as mulheres ficaram em silêncio, no Brasil, durante mais de trezentos anos. Este silêncio se fez, não porque elas estivessem omissas ou passivas ao longo da história nacional, mas foi um silêncio imposto pela reconstrução histórica, pela ausência de documentação, ou sua presença em documentos e manuscritos de difícil acesso.

Em 1842, surge a primeira mulher que se destacou como líder político, Da. Josefa Carneiro de Mendonça, que trabalhou em prol da revolução de Minas Gerais. Na metade do século passado, Nísia Floresta Augusta Brasileira foi a primeira mulher a defender publicamente a emancipação da mulher no Brasil.

É interessante registrar a expansão de jornais editados por mulheres, no final do século passado, em São Paulo e no Rio de Janeiro. Dentre eles, temos: "Jornal das Senhoras" (1852); a revista "A Familia"; "O Sexo Feminino" (de 1885-1890), que pregavam os direitos da mulher em prol da instrução feminina e o direito ao voto. Em 1905, Ernestina Lesina funda o jornal destinado às trabalhadoras, o "Anima Vita".

Em 1870, no Rio de Janeiro, as mulheres se 
organizam em detesa dos escravos, integrando o movimento abolicionista e criam "A Sociedade da Libertação", e, em São Paulo, a "Sociedade Redentora", com a mesma finalidade (CARDOSQ) ${ }^{7}$.

No começo do século, ocorreram manifestações de operárias, em conseqüência do processo da industrialização, que utilizava a mão-de-obra feminina nas piores condições. Em 1917, Leoninda Castro organiza uma passeata no Rio de Janeiro, pelo direito ao voto. Em 1919, uma delegação de brasileiras, integrada por Bertha Lutz e Ulga Paiva Meira, representa o Brasil no Conselho Feminino Internacional da Organização Internacional do Trabalho (OIT). Nesse mesmo ano, cria-se a "Liga para a Emancipação Intelectual da Mulher", que defende o direito ao voto feminino (BARRO$\mathrm{SO})^{3}$.

A fundação do Partido Republicano Feminino, em 1910, é bastante importante na luta pelo voto entre as mulheres de classe média, prof essoras primárias e profissionais liberais. Após a Revolução de 1930, o direito ao voto é assegurado às mulheres no Código Eleitoral de 1932.

O período pós-guerra foi marcado, em todo o País, pelo recrudescimento das atividades relacionadas à conquista das liberdades democráticas. Assim, no Rio de Janeiro, as mulheres fundaram junto à União Nacional dos Estudantes - UNE, o Comitê das Mulheres pela Anistia que, uma vez conquistada a anistia polítică, se transformou no Comitê das Mulheres pela Democracia. As ligas femininas, criadas a partir de 1944 e atuantes até 1964, lutavam contra a demolição das favelas, faziam campanhas para instalação de creches e bibliotecas infantis, e lutavam pela independência econômica nacional e contra a carestia.

Em 1962, surge no Código Civil o reconhecimento da mulher como capaz, do pon to de vista civil.

Após a revolução de 1964, as atividades femininas transformaram-se em grupos beneficentes. Seus trabalhos são fundamentados em trabalhos comunitários e no sindicalismo paralelo. Quando, em 1975, a ONU batizou este ano como "Ano Internacional da Mulher", surgiram os primeiros grupos feministas em São Paulo e Rio de Janeiro $\left(\right.$ BARROSO) ${ }^{3}$. As bandeiras de luta são semelhantes ao passado: a anistia, a carestia, a conquista pela democracia.

É dentro desse quadro de reivindicações que a mulher coloca, através da imprensa feminista, que se inicia em 1976, sua posição específica como trabalhadora mais discriminada, como cidadã sem direitos, como mulher oprimida. A diferença com o passado é que tla passa, agora, a se organizar de forma independente do Estado, da Igreja e dos Partidos Políticos.

Apesar disso, ainda é pequena a participação da mulher na vida sindical e na vida partidária e parlamentar, aparecendo muito mais como massa do que cúpula dirigente.

d) A Situação de Saúde da Mulher

A análise das condições de saúde da mulher brasileira supõe uma avaliação sobre a situação geral da saúde no Brasil. Habitualmente, este tipo de análise é dificultado pela carência de dados em relação às mulheres não incluídas nas categorias de gestantes e nutrizes.

A evolução da situação de saúde das mulheres brasileiras demonstra, de certa forma, precariedade no atendimento às necessidades de saúde da população. Ainda predomina a idéia de que as necessidades de saúde das mulheres restringem-se aos cuida dos durante a gravidez, par to e puerpério.

A mulher brasileira tem visto sua esperança de vida aumentada ao longo deste século, especialmente a partir dos anos 50. Entre os anos de 1970-76, modificou-se a taxa de fecundidade, verificando-se uma queda da taxa para $4,3 \%$, e foi nas famnlias mais pobres onde essa queda ocorreu de forma mais acentuada (BARROSO) ${ }^{3}$.

$\mathrm{O}$ uso de anticoncepcionais aumentou extraordinariamente em nosso País, nos últimos anos. O Brasil está em fase de legalização do aborto, sem contudo se ter certeza de que haverá realmente uma diminuição da taxa de mortalidade por aborto, conforme ocorreu em alguns paises. BARRO$\mathrm{SO}^{3}$ salienta a ocorrência da prática da esterilização pela população feminina de nível mais baixo, em nossos dias.

Há escassez de informações a respeito dos efeitos específicos das atividades das mulheres em sua saúde; a maioria dos estudos focaliza os efeitos sobre o fato e ignora a própria mulher.

$\mathrm{O}$ incentivo à amamentação pelos órgãos governamentais nacionais e internacionais esquece, em seu conteúdo de campanha, a realidade social e legal que obstaculiza a amamentação. Enfatiza-se apenas a responsabilidade da mulher, acabando, tão-somente, por gerar um sentimento de frustração.

Em 1974, a legislação previdenciária transf eriu para o INPS todos os encargos com relação à licença gestação, que abrange quatro semanas antes do parto e oito semanas após o parto.

A partir das idéias discutidas em Copenha- 
que, 1980, na Conferéncia das Nações Unidas, sobre a situação da mulher, os ministérios da Saúde e da Previdência e Assistência Social explicitaram em suas diretrizes, a qualidade de dependencia da mulher, a quem seria oferecida assistência social. E, assim, a partir de 1983, começa a ser implantado o "Programa Integral da Saúde da Mulher", desenvolvido śob a orientação do Ministério da Saúde.

Desta forma, percebe-se que, se a mulher conseguiu alguns espaços em determinados setores da sociedade brasileira, isto não indica que toda a discriminação que existia em relação ao sexo feminino tenha sido elimina da. $\mathrm{O}$ fato histórico não pode ser considerado como definindo uma verdade e terna; traduz apenas uma situação que se manifesta precisamente como histórica porque está mudando.

\section{III - A EVOLUÇĀO HISTÓRICA DA ENFERMAGEM BRASILEIRA}

Relatar a evolução histórica de uma profissāo é um assunto de grande abrangência, se considerarmos que esta evolução ocorre dentro de um contexto social, político e econômico que gera as situações responsáveis por aquilo que evolui.

Uma análise destes aspectos por si só constituiria uma monografia, o que nos leva neste trabalho a apenas narrar os fatos que, do nosso ponto de vista, em sua essência, consistem em ampliação do espaço da enfermagem como profissão.

$O$ ensino elementar de enfermagem teve início em 1890 com o objetivo de treinar pessoal para os hospícios e hospitais militares, seguido pela Cruz Vermelha que, em 1916, passou a preparar socorristas de emergência e, em 1920, visitadoras sanitárias (CARVALHO) ${ }^{8}$.

Segundo o documentário de CARVALHO ${ }^{8}$, a criação do Serviço de Enfermeiras do Departamento Nacional de Saúde Pública (DNSP), em 1922, nos moldes do sistema americano, deu origem à Escola de Enfermeiras do Departamento Nacional de Saúde Pública, regulamentada em 1923. Foi esta a primeira escola a visar um padrão mais elevado de ensino, por preocupação do diretor geral do DNSP, médico sanitarista Carlos Chagas, admitindo apenas candidatas que tivessem o diploma de Escola Normal ou equivalente.

Esta escola de enfermagem surgiu sob a égide da saúde pública e, segundo BARROS ${ }^{2}$, a prática profissional visava o atendimento de um segmento da comunidade exposto aos riscos das doenças transmissíveis epidêmicas na época, o que ocasionava um decréscimo da mão-de-obra necessária à produção econômica, bem como dificuldades à imigração dos estrangeiros para o País.

Data de 1926 a criação da ABEn (CARVALHO $)^{8}$ que, em 1929, filiou-se ao Conselho Internacional de Enfermeiras, propiciando às enfermeiras diplomadas do Brasil um vínculo internacional. Esta Associaçāo inicia a divulgação do primeiro periódico de Enfermagem, em 1932.

A década de 30 marca a desvinculação da Escola de Enfermagem do DNSP. Pelo Decreto no 20109/31, foi elevada a escola oficial padrão e designada Escola de Enfermeiras Ana Neri. Em 1937, foi incorporada à Universidade do Brasil como instituição de ensino complementar, com completa autonomia, mantendo-se ainda a nível médio de ensino (BRASIL. Ministério da Saúde/FSESP) 5 .

E neste período que a prática de enfermagem começa a se voltar para o ambiente hospitalar e ampliar-se nos trinta anos que se seguiram em detrimento das ações de saúde pública (BARROS) ${ }^{2}$.

ALMEIDA et alii ${ }^{1}$ situam a predominância da enfermagem hospitalar em 1950, quando 49,4\% das enfermeiras atuantes encontravam-se no campo hospitalar e 17,2\% no campo da saúde pública. Já em 1944, registrava-se uma situação inversa, vez que $66 \%$ das enfermeiras diplomadas pela Ana Neri trabalhavam no campo da saúde pública e $9,5 \%$, em hospitais.

Caracteriza-se assim a limitação de espaço de ação, primeiro em saúde pública e depois na área hospitalar, ao invés da expansão do espaço já conquistado em saúde pública, se a ele viesse sem o prejuízo da primeira.

CARVALHO $^{8}$ registra como 1940 a inclusão dos enfermeiros entre os profissionais liberais no quadro de atividades e profissões do Ministério do Trabalho, Indústria e Comércio. No entanto, três anos depois perderiam esta posição em virtude da intervenção do Sindicato dos Enfermeiros e Empregados em hospitais e Casas de Saúde do Rio de Janeiro junto ao Ministério do Trabalho. O direito de profissional liberal para fins de enquadramento sindical só foi reconquistado em 1962.

Em 1955, foi sancionada a lei no 2604/55, que regulamenta o exercício profissional (BRASIL. Ministério da Saúde/FSESP), ${ }_{1}^{5}$. Embora esta lei atribua à enfermeira responsabilidade pelo ensino nas escolas de enfermagem e de auxiliares bem como supervisão e controle do pessoal auxiliar, mantém e legítima a subordinação de muitas açōes de enfermagem à medicina. 
Em 1962, os cursos de enfermagem, até então de nível médio, passaram a nível universitário, sendo o currículo mínimo determinado pelo Parecer no 271/62 CFE. Foram mantidos, no entanto, os cursos de formação de pessoal auxiliar a nívêl de 10 e 2 graus, incluindo-se em 1966 mais uma categoria, a do técnico de enfermagem (BRASIL. Ministério da Saúde/FSESP) ${ }^{5}$.

A marca seguinte na evolução da enf ermagem é a criação dos Conselhos Federal e Regionais de Enfermagem, pela Lei no 5905/73 da Presidência da República, instalados em 1975, cuja atribuição consiste em fiscalizar o exercício profissional em todo território nacional (CARVALHO) ${ }^{\mathbf{b}}$.

Segundo SILVA ${ }^{13}$, ao passar a nível universitário, o ensino da enfermagem evidenciou a busca de auto-afirmar-se no campo da ciência, destacando-se a ênfase no ensino do "processo de enfermagem" ou "processo decisório".

Novos espaços foram conquistados pelo ensino em 1972, a saber: a modificação do currículo mínimo de enfermagem pelo parecer 163/72 do CFE, no qual foram criadas habilitações nas áreas de saúde pública, obstetrícia e ginecologia e em médico-cirúrgica, e cursos de pós-graduação em enfermagem, disposições sobre o funcionamento pela Resolução 6/72 do CFE (BRASIL. Ministério da Saúde/FSESP) ${ }^{5}$.

Os cursos de pós-graduação começaram a surgir com a preocupação maior de preparar docentes e pesquisadores viabilizando, assim, a incrementação da produção científica.

Com o objetivo de sistematizar e divulgar as produções científicas da área, foi criado pela ABEn, em 1971, o Centro de Estudos e Pesquisas em Enfermagem (CEPEn).

Em relação à expansão dos cursos de pós-graduação, de um levantamento (1978 a 1980) constam quarenta instituições envolvidas com cursos de pós-graduação, das quais nove ministrando cursos stricto sensu e trinta e uma, cursos lato sensu $(\text { WRIGHT })^{14}$.

Outro fato significativo a ser relatado é o surgimento do Sindicato dos Enfermeiros, sendo o primeiro em 1976 (Rio Grande do Sul) e, atualmente, em número de 6: Rio Grande do Sul, Rio de Janeiro, Bahia, Distrito Federal e Ceará.

Configura-se assim que, em mais de 50 anos de existência da profissão, as conquistas legais, tanto na área de ensino como na prática profissional, ocorreram lentamente, deixando ainda em aberto grande espaço a ser conquistado na sociedade brasileira.

\section{IV - OS CONDICIONANTES NA CONQUISTA DE UM ESPAÇO}

A discriminação existente em relação às minorias, em especial contra o sexo feminino, aparece porque as mulheres nunca formaram uma sociedade autônoma e fechada; elas fazem parte de uma coletividade governada por homens e na qual ocupam um lugar de subordinadas. Surge daí o paradoxo de sua situação: elas pertencem ao mesmo tempo ao mundo masculino e a uma esfera em que este mundo é contestado. Por outro lado, as mulheres não têm domínio sobre o mundo masculino porque sua experiencia não lhes ensina a manejar a lógica e a técnica (BEAUVOIR) ${ }^{4}$.

Isto vem ocorrendo desde o Brasil Colônia, quando o Governo e as Instituições Religiosas impuseram, além do ensino religioso às mulheres, 0 de costura, bordado, lavar roupa, tudo aquilo que constituía os bons costumes. Compreende-se, portanto, porque a mulher não podia ter qualquer participação e porque era submissa a temerosa (CARDOSO) ${ }^{7}$.

Por outro lado, os grupos dirigentes começaram a perceber que, se a mulher podia educar as crianças como mãe, também poderia dar aulas a elas na escola. Assim, começa uma dupla exploração do papel da mulher - o desempenho das tarefas domésticas e a desprestigiada e mal remunerada tarefa do magistério.

Apesar do surgimento de idéias liberais quanto à atividade da mulher fora do lar, a lgreja Católica tudo fazia para afirmar que a mulher era diferente do homem biologicamen te, devendo também ser desigual civil e politicamente, dificultando assim as transformações sociais que se iniciavam.

As idéias positivistas que começaram a ser divulgadas no Brasil na época da República, atuaram como obstáculo à independência da mulher porque, dentro desta filosofia, o homem é quem trabalha fora de casa ficando os velhos, as crianças e as mulheres amparados por ele.

Embora a opinião pública percebesse a necessidade de um tratamento eqüitativo para as mulheres como ponto fundamental ao desenvolvimento da nação, a história caminhou mais lentamente.

Neste lento processo de emancipação da mulher, surge a permissão para que ela avance seus estudos, cursando o 2 ? grau e inclusive o superior; no entanto, ela só tenta concluir este último quando começa a perceber que o casamento não consti. tui uma estrutura de segurança. Assim, passa a escolher profissões que ficaram, tradicionalmente, 
para as mulheres, estando com isto pré-determinado o lugar onde ela vai trabalhar, sem levar em conta sua vocação.

A irrelevância atribuída à vocação para a profissionalização da mulher decorre, entre outros fatores, desta ter sido relegada à esfera doméstica, pela divisão do trabalho entre os sexos, incentivada pelo sistema patriarcal, o qual dividiu a vida social em duas esferas nitidamente dissociadas: a esfera pública e a esfera doméstica. Desta forma, começa a surgir uma ideologia que ainda hoje delineia a imagem da mulher e o seu papel na vida social (LARGUIA \& DUMOULIN) $)^{11}$.

Para melhor compreender a evolução do nível de participação da mulher na força de trabalho, é necessário visualizar o contexto em que esta ocorreu. Espera-se que, em um primeiro momento, ela ocorra na abertura da industrialização quando o número de pessoas empregadas na agricultura é ainda elevado e o número de empresas manufatureiras e comerciais limitado à esfera doméstica. Em um segundo momento, quando o desenvolvimen to econômico induz um grande número de pessoas a sair do comércio e da fabricação caseira e há paralelamente uma migração de áreas rurais para áreas urbanas, a taxa de participação da mulher em atividades produtivas, tende a cair. $\mathrm{O}$ terceiro momento é quando há um crescimento contínuo no setor de serviços (BARROSO) ${ }^{3}$.

Entre os setores de serviços, destaca-se, para este trabalho, o setor de assistência à saúde, no qual configura-se, na maneira de organizar o processo de trabalho, a forma associada, isto é, equipes multiprofissionais, cujo produtor principal é o médico. Essa condição lhe assegura a hegemonia do controle técnico-profissional do cuidado do paciente, mediante prescrições de atos que serão executados por outros profissionais.

Este sistema de produzir serviços de saúde determina que a enfermagem, profissão predominantemente feminina, seja considerada, ao nível de mercado de trabalho, como uma força de trabalho assalariada, que executa parcelas simples do processo produtivo. Conseqüentemente, a enfermeira é contratada não para prestar uma assistência em função das necessidades da população, mas para realizar o que os empregados determinam, isto é, ela entra na composição da estrutura ocupacional na medida exata para executar o controle dos atos prescritos (SANTOS \& VIEIRA) ${ }^{12}$.

Os aspectos sociais influenciam a maneira com que a mulher se empenha em sua profissão e a ela se dedica, pois isto depende do contexto consti- tuído pela forma global de sua vida. No seu cotidiano, a mulher é prisioneira da sociedade de consumo e isto é manifestado claramente, tanto quando desempenha seu papel social quanto profissional. Os cânones básicos de beleza que reina no mercado, possuem um marcado caráter de classe, não só em função de aumentar o ritmo de produção das indústrias mas, fundamentalmente, a de infiltrar, na consciência das classes exploradas os valores estéticos e morais da classe dominante. Profissionalmente, isto implica na escolha do material utiliza do no desempenho de suas funções profissionais (BEAUVOIR) ${ }^{4}$.

Por outro lado, os preconceitos sociais criados pela sociedade impõem conotações positivas ou negativas não só em relação a atitudes pessoais como também à profissão, enquanto comportamento de um grupo. Assim, a enfermagem como atividade de execução predominantemente manual é relacionada ao trabalho de baixa qualificação e, portanto, desprestigiada socialmente (SILVA) ${ }^{13}$.

Uma outra possível explicação para as dificuldades que a mulher-enfermeira encontra na sociedade, poderia advir do fato de que, em sua maioria, as mulheres que trabalham não se evadem do mundo feminino tradicional, além de não receberem da sociedade e nem do marido a ajuda que lhes seria necessária para se tornarem concretamente iguais aos homens. Assim, ela fica dividida entre seus interesses profissionais e as preocupaçōes domésticas, tendo dificuldades para encontrar um equilíbrio para os dois papéic.

Ao mesmo tempo, não recebendo em troca de seu trabalho os benefícios morais e sociais com que estariam no direito de usufruir, a mulher cria em si mesma um complexo de inferioridade, levando-a a duvidar de suas possibilidades profissionais. Em conseqüência disto, a mulher acomoda-se facilmente com um êxito medíocre, não ousa tẹr maiores aspirações, abordando seu of ício com uma formação superficial, colocando assim um limite em suas ambições (BEAUVOIR) ${ }^{4}$.

Desta forma, mesmo que a mulher tenha dado um passo à frente com sua incorporação no trabalho visível, ela o faz a troco de um sacrifício que é convenientemente silenciado pelas classes dominantes. Isto é, trabalha 8 horas por dia recebendo, por isso, um salário e ao voltar para casa espera-a uma segunda jornada de trabalho não assalariada que constitui o produto invisível de sua força de trabalho (LANGUIA \& DUMOULIN) ${ }^{11}$. Este fato continua sendo vivido e ignorado nos dias de hoje. 


\section{V - CONSIDERAÇÕES FINAIS E CONCLUSŐES}

A análise geral do contexto histórico $\mathrm{da}_{3} \mathrm{mu}$ lher evidencia que os espaços permitidos para ela surgiram pela situação estrutural que os exigia, isto é, não ditados pela mulher. As mulheres estão unidas somente enquanto semelhantes por uma solidariedade mecânica, não há entre elas essa solidariedade orgânica em que assenta toda uma comunidade unificada; elas se esforçam sempre, desde os primórdios até hoje, nos clubes, nos salões, nas reuniões beneficentes, por se ligarem, a fim de afirmarem um "contra universo", mas é ainda no seio do universo masculino que o colocam.

No decorrer do trabalho, percebe-se que a sociedade ensinou a mulher a aceitar a autoridade masculina, e assim ela renuncia a criticar, a examinar, a julgar por conta própria mostrando, portanto, um dos traços de seu caráter - a resignação.

A situação na sociedade brasileira é manifestada a través do conjunto de características que compõem seu caráter, dentre elas, as convicções, os valores, a sabedoria, a moral, os gostos e as condutas.

A simples justaposição do direito ao voto e o direito a uma profissão não constitui uma efetiva conquista de espaço da mulher na sociedade.

Não se pode perder estes fatos de vista quando se relaciona o espaço ocupado pela mulher-enfermeira, porque a situação mostra também que este não foi ditado por elas, mas pelas políticas governamentais que dominam o setor saúde, desde os primórdios até hoje, e também a divisð̃o social do trabalho.

WHIGHT, M. G. M. \& CARNEIRO, A. Brazilian woman territory and the brazilian nurse territory. Rev. Bras. Enf., Brasília, 38(1):55-62, jan./mar. 1985.

\section{REFERENCIAS BIBLIOGRÁFICAS}

1. AlmeidA, M. C. P. et alii. Contribuição ao estudo da prática da Enfermagem - Brasil. s.n.t. (mimeografado).

2. BARROS, S. M. P. F. Enfermagem social - seu objeto de trabalho. In: CONGRESSO BRASILEIRO DE ENFERMAGEM, 33, Manaus, 2 a 7 de agosto, 1981. Anais... Manaus, ABEn, 1981. p. 153-9.

3. BARROSO, C. Mulher, sociedade e estado no Brasil. São Paulo, Brasiliense, Fundo das Nações Unidas para a Infância (UNICEF), 1982.

4. BEAUVOIR, S. O segundo sexo; a experiência vivida. Rio de Janeiro, Nova Fronteira, 1980, v. 2.

5. BRASIL. Ministério da Saúde. Fundação Serviços de Saúde Pública. Enfermagem; legislação e assuntos correlatos. Rio de Janeiro, Fundação Serviços de Saúde Pública, 1974. 3v.

6. BRUSCHINI, M. C. A. Sexualidade das ocupações; o caso brasileiro. Cadernos de Pesquisa. São Paulo, 28:5-20, 1979.

7. CARDOSO, I. Os tempos dramáticos da mulher brasileira. São Paulo, Centro Editorial Latino-Americano, 1981.

8. CARVAlho, A. C. Associação Brasileira de Enfermagem, 1926-1976; documentário. Brasília, ABEn, 1976.

9. DOURADO, H. G. \& COELhO, C. P. Nursing and child health in Brazil. Int. Nurs. Rev., 27(3): 70-5, May/Jun. 1980.

10. HAHNER, J. E. A mulher no Brasil. Rio de Janeiro, Civilização Brasileira, 1978.

11. LARGUiA, I. \& DUMOUliN, J. Para uma ciência da libertação da mulher. São Paulo, Global, 1982.

12. SANTOS, I. \& VIEIRA, C. A. B. Análise crítica da prática atual de enfermagem no país. In: CONGRESSO BRASILEIRO DE ENFERMAGEM, 31, Fortaleza, 5 a 11 de agosto, 1979. Anais... Fortaleza, ABEn, 1979. p. 85-91.

13. SILVA, G. B. Desenvolvimento da enfermagem, correlação dos problemas da profissão e da mulher sociedade. In: CONGRESSO BRASILEIRO DE ENFERMAGEM, 31, Fortaleza, 5 a 11 de agosto, 1979. Anais... Fortaleza, ABEn, 1979. p. 27-32.

14. WRIGHT, M. G. Avaliação e perspectivas. Brasília, SEPLAN/CNPq, 1982. (Ciências da Saúde, Enfermagem, v. 6. n. 38). 